\title{
Temporal adaptations in generic and population-specific quality of life and falls efficacy in men with recent lower-limb amputations
}

\author{
Cleveland T. Barnett, PhD; ${ }^{*}$ Natalie Vanicek, PhD; ${ }^{2}$ Remco C. J. Polman, $\mathbf{P h D}{ }^{\mathbf{3}}$ \\ ${ }^{1}$ SHAPE Research Group, School of Science and Technology, Nottingham Trent University, Nottingham, UK; \\ ${ }^{2}$ Discipline of Exercise and Sport Science, Faculty of Health Sciences, University of Sydney, Sydney, Australia; and \\ Department of Sport, Health and Exercise Sciences, University of Hull, Hull, UK, ${ }^{3}$ Institute of Sport, Exercise and \\ Active Living, Victoria University, Melbourne, Australia
}

\begin{abstract}
This study examined the longitudinal changes in generic health-related quality of life (QOL), prosthesis-related QOL, falls efficacy, and walking speed in men with lower-limb amputations up to 6 months following discharge from rehabilitation. Seven male unilateral transtibial amputees completed the Medical Outcomes Study 36-Item Short Form Health Survey, the Prosthesis Evaluation Questionnaire, and the Modified Falls Efficacy Scale at 1,3, and 6 months postdischarge from rehabilitation. Walking speed was also recorded to objectively assess participants' mobility. Health-related QOL measures displayed increases, resulting in large effect sizes though not reaching statistical significance. Prosthesis-related QOL measures indicated that scales relating to the participants' prostheses improved and the support of significant others was the most positively scored variable. Walking speed increased by $0.12 \mathrm{~m} /$ $\mathrm{s}$, although it was not significantly related to indices of QOL or falls efficacy. Falls efficacy did not improve significantly during the study period, although it was strongly related to QOL $(p<0.05)$. These results provide a novel insight into how QOL and falls efficacy develop in people with lower-limb amputations, alongside changes in mobility, after discharge from rehabilitation. Further improvements in physical health following discharge may be required to elicit subsequent increases in overall QOL and concurrent improvements in falls efficacy.
\end{abstract}

Key words: amputee, adaptations, falls efficacy, longitudinal, mFES, PEQ, quality of life, rehabilitation, SF-36, transtibial.

\section{INTRODUCTION}

Experienced transtibial prosthesis users are able to complete activities of daily living (ADLs) effectively, and the successful completion of these tasks is an integral part of regaining an independent lifestyle [1-5]. However, psychological issues, such as how an amputee feels about his or her amputation and prostheses, are also important factors. Previous reports have suggested that in order to provide a complete assessment of the benefits of an intervention, evidence of its effect on health-related quality of life (QOL) must be reported [6-8]. People with recent lower-limb amputations will continue to adapt to using a prosthetic limb during ADLs as they rejoin the work place and participate in recreational activities including sport and exercise [9-10]. These adaptations may lead to changes in an amputee's physical abilities and will likely have an effect on self-reported QOL.

\footnotetext{
Abbreviations: $\mathrm{ADL}=$ activity of daily living, $\mathrm{MCS}=$ Mental Health Component summary, mFES = Modified Falls Efficacy Scale, $\mathrm{PCS}=$ Physical Component summary, PEQ $=$ Prosthesis Evaluation Questionnaire, QOL $=$ quality of life, SF-36 = 36Item Short Form Health Survey.

*Address all correspondence to Cleveland T. Barnett, PhD; School of Science and Technology, Nottingham Trent University, Clifton Lane, Nottingham, NG11 8NS United Kingdom; 0115-848-3824. Email: cleveland.barnett@ntu.ac.uk http://dx.doi.org/10.1682/JRRD.2011.10.0205
} 
Reports of QOL have varied, with people with lowerlimb amputation being equal to or higher [11-12] and lower [8-10,13-14] than normative reference data, indicating that no general consensus exists on how amputation affects QOL. However, a higher level of amputation (e.g., transfemoral vs transtibial) has been associated with decreased QOL [15]. Mental health is reportedly higher than physical health in people with lower-limb amputations, although studies have found physical health is more closely related to overall QOL [9-13,16-18]. Factors affecting mental health include depression, which is considered an important predictor of QOL [11], as well as the aesthetics of the prosthesis [13,16] and employment status [8]. Studies have also shown QOL to be highly related to both the physical [13-14] and social [19] aspects of an amputee's life, as well as being closely associated to the functioning of his or her prosthesis $[8,12-13]$.

Assessment of the temporal aspects of QOL in people with lower-limb amputations has been limited $[12,20]$. Studies have linked physical functioning with QOL and reported stable levels of QOL across rehabilitation $[12,20]$. Zidarov et al. referred to a "response phenomena" when interpreting results, suggesting that as people with amputations regained physical capacity, expectations of physical ability also increased, resulting in a consistent level of QOL being reported. Coupled with the links between walking ability and QOL [20], results have suggested that as people with amputations regain mobility, there is a positive effect on QOL.

Increased QOL may also have a beneficial effect on an amputee's fear of falling. Falls efficacy is reportedly reduced in people with amputations when compared with a community-dwelling elderly population [21-23]. This finding has been attributed to the fact that people with lowerlimb amputations expect to fall because of their physical constraints or while attempting tasks of increasing difficulty [22]. Although a fear of falling has been linked with reduced QOL, the longitudinal aspects of falls efficacy in people with lower-limb amputations have not been thoroughly investigated, nor has an amputation-specific measure of falls efficacy been developed [22-23].

Although a profile of lower-limb amputee QOL and falls efficacy has been presented, the literature points to a paucity of longitudinal studies in this area of research [14]. Understanding the changes that occur in QOL and falls efficacy over time following discharge from rehabilitation is important for this population. This may have long-term implications with regards to mobility and social reintegration as well as participation in future physical activity and employment.

\section{PURPOSE AND OBJECTIVES}

The current study had five objectives, all of which investigated changes reported from a unilateral transtibial amputee population in variables across three time points: 1 month, 3 months, and 6 months postdischarge from rehabilitation. The objectives were to-

1. Investigate changes in generic health-related QOL, using the Medical Outcomes Study 36-Item Short Form Health Survey (SF-36).

2. Investigate changes in prosthesis-related QOL, using the Prosthesis Evaluation Questionnaire (PEQ).

3. Examine the changes in falls efficacy using the Modified Falls Efficacy Scale (mFES).

4. Examine the relationship between falls efficacy and indices of QOL (factors of SF-36).

5. Examine the relationship between an objective measure of mobility (walking speed) and indices of QOL (factors of SF-36) and falls efficacy.

\section{METHODS}

\section{Participants}

The initial approach to participate in the study was made by the physiotherapy team, and participants consented to be contacted by the principal investigator following their final physiotherapy treatment. Seven male unilateral transtibial amputees participated in the current study, having followed a course of rehabilitation within a National Health Service physiotherapy department (Table 1). Initially, participants had the study explained to them by physiotherapists and agreed to be contacted by the principal investigator.

\section{Ethical Considerations}

Inclusion criteria stipulated that participants had a unilateral transtibial amputation and were at least $18 \mathrm{yr}$ of age. Participants were required to have completed specialist amputee rehabilitation within the previous 4 weeks before consenting to participate in the study. Further inclusion criteria required participants to be able to use their prosthesis without pain or discomfort and complete a number of 
Table 1.

Individual characteristics of participants with unilateral transtibial amputations.

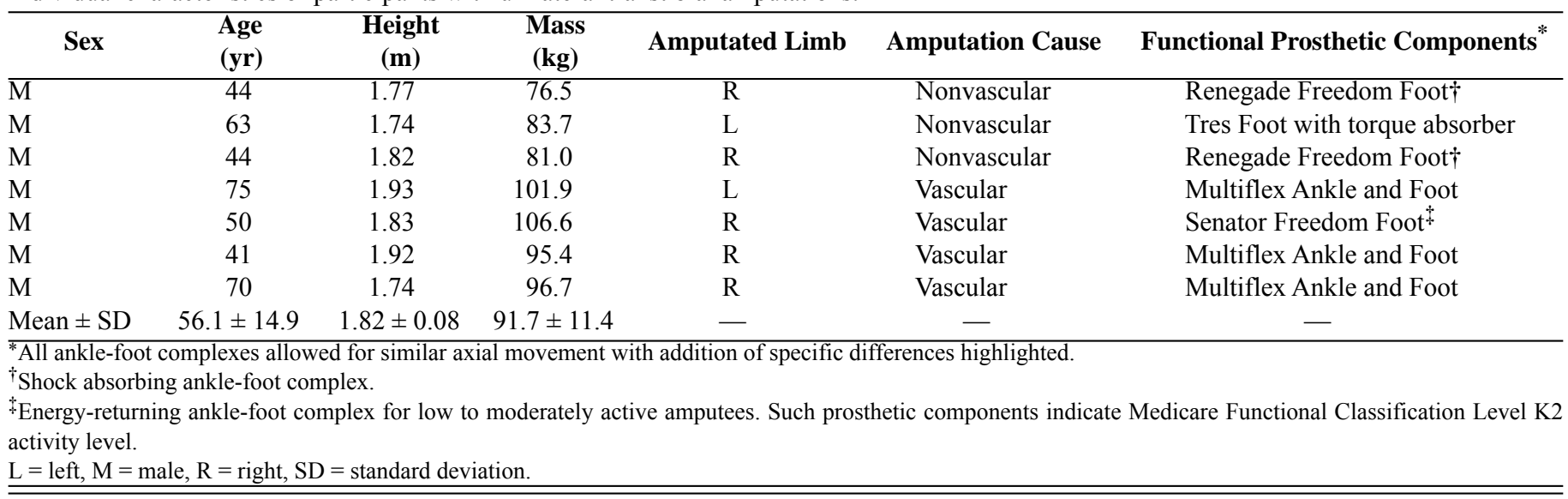

functional tasks without the use of a walking aid, for example, walking $5 \mathrm{~m}$ and stepping over an obstacle. The suitability of a participant's ability to complete these tasks was assessed by experienced physiotherapists who regularly dealt with lower-limb amputee rehabilitation.

Participants were excluded from the current study if they had any current musculoskeletal injuries or cognitive deficits. Participants were also excluded if they had a bilateral or transfemoral amputation. Lastly, participants were excluded if they did not use their prosthesis regularly or experienced pain or discomfort while doing so.

\section{Instruments and Data Analysis}

The questionnaires were collected and scored by the same researcher, and the data were manually inputted into a Microsoft Excel workbook (Microsoft Corp; Reading, United Kingdom). Walking speed (meters per second) was recorded using a 10-camera motion capture system (Qualisys; Gothenburg, Sweden) as participants walked along a $10 \mathrm{~m}$ walkway. Participants walked at a self-selected pace during a gait analysis testing session, providing objective data regarding mobility.

\section{Medical Outcomes Study 36-Item Short Form Health Survey}

The Medical Outcomes Study SF-36 is a generic measure of health status and is one of many available tools that allow clinicians and researchers to assess selfreported QOL [24]. The SF-36 produces an eight-scale profile of health, namely Physical Functioning, Role Physical, Bodily Pain, General Health, Vitality, Social Functioning, Role Emotional, and Mental Health. It also produces a Physical Component summary (PCS) and
Mental Health Component summary (MCS), as well as an overall or total QOL score [6].

Although there is no amputation-specific version of the SF-36, the paper-based UK version of the SF-36 was used to assess changes in transtibial amputee generic health-related QOL in the current study. The SF-36 has been used previously to assess QOL in people with lower-limb amputations of varying levels [9-10,25-26], suggesting it is a valid tool for use with this population.

The SF-36 scoring system is such that a higher score indicates improved health status in relation to that scale. Scoring of the SF-36 follows a three-step procedure according to the author guidelines: item recoding, raw scale score computing, and transformed scale score computing [24]. The item-recoding procedure involved taking the manually inputted raw precoded data and assigning a recoded value to each item score. Once the data had been recoded, a raw scale score was calculated as a simple algebraic sum of the item responses for a particular scale. Once the raw scale score had been calculated, it was then transformed.

Transformation of the raw scale scores to a $0-100$ scale allowed for comparison between studies, including those using different or previous versions of the SF-36 [24]. In addition to the transformed scores for each of the eight SF36 scales, it is possible to compute higher order dimension scores for the PCS and MCS as an arithmetic mean of the associated scale scores. A total SF-36 score was computed as the arithmetic mean of the PCS and MCS.

\section{Prosthesis Evaluation Questionnaire}

The PEQ is a measure of prosthesis-related QOL developed for use within rehabilitation research because 
of the lack of a specific lower-limb amputation or prosthesis-related QOL measure [27]. The PEQ consists of 82 items; 42 of these items produce a nine-scale profile of health, namely Ambulation, Appearance, Frustration, Perceived Response, Residual-Limb Health, Social Burden, Sounds, Utility, and Well-Being. The scales are independent and can be assessed in isolation. Some of these scales pertain to more generic QOL issues, such as Social Burden, whereas others are more specific to people with lower-limb amputations, such as Residual-Limb Health. The PEQ has been used in a variety of scientific investigations pertaining to people with lower-limb amputations that have provided evidence for the efficacy of the PEQ and its subscales in the assessment of prosthesis health-related QOL [11,22-23,28-29].

Scale scores for the PEQ were calculated using the arithmetic mean of the item scores contained within the relevant scale. The scoring system of the PEQ is such that a higher score indicates a more positive score. At least half the items within a specific scale must be answered to retrieve a valid scale score. Because the scales were individually validated and tested for reliability, each scale can be used and interpreted individually.

\section{Modified Falls Efficacy Scale}

The mFES is a self-report measure of an individual's self-perceived ability to complete a task without falling [30]. The mFES consists of 14 items aimed at assessing falls efficacy during both indoor and outdoor activities. Examples of the 10 items assessing indoor activities are getting dressed and bathing; crossing roads and using public transport are examples of the 4 outdoor activities assessed. The mFES has been used in empirical research investigating falls within a community-dwelling elderly population [31], improvements in fall rates in the elderly via training [32], and in analyses of the effect of fear of falling on gait in the elderly [33].

The overall mFES score was calculated as the arithmetic mean of all 14 item scores. The scoring system of the mFES is such that a higher score indicates greater falls efficacy. The arithmetic mean of relevant items was used to calculate Factor One (indoor activities), Factor Two (outdoor activities), and total or overall mFES scores.

\section{Experimental Design and Protocol}

Participants attended a standardized number of data collection sessions at 1,3 , and 6 months postdischarge from rehabilitation, during which they were required to complete the SF-36, PEQ, and mFES upon arrival at the Human Performance Laboratory and before walking along a $10 \mathrm{~m}$ walkway at a comfortable, self-selected walking speed. Participants were encouraged to respond to questions based on their own interpretation, and if required, questions were repeated verbatim by the researcher.

\section{Statistical Analysis}

Group averaged mean values were used for statistical analysis. A repeated measures analysis of variance was performed with repeated measures on the factor of time (1 month, 3 months, 6 months). In relation to the study aims, this statistical model allowed for the analysis of changes in multiple measures of QOL, falls efficacy, and walking speed. The underlying assumption of sphericity of the data was verified, and where this was violated, adjustments to the degrees of freedom following the Greenhouse-Geisser method were applied. In the instance of a significant time main effect, post-hoc comparisons were conducted using a Sidak adjustment. Estimates of effects sizes were reported as partial-eta squared $\left(\eta_{\mathrm{p}}{ }^{2}\right)$ with their magnitude being interpreted using the convention of 0.0099 (small effect), 0.0588 (medium effect), and 0.1379 (large effect) [34]. The relationships between QOL and falls efficacy and between walking speed, QOL, and falls efficacy were assessed using Pearson correlation coefficient $(r)$. The underlying assumption of normality of the data was verified using the Shapiro-Wilk test, and where this was violated, data were analyzed using Spearman correlation coefficient $\left(r_{s}\right)$. Estimates of the strength of relationships were interpreted using the convention $0.10-0.29$ (weak), 0.30-0.49 (medium) and 0.50-1.00 (strong) [34]. All statistical tests were conducted using IBM SPSS 19.0 (IBM UK Ltd; Portsmouth, United Kingdom). The alpha level of statistical significance was set at $p \leq 0.05$.

\section{RESULTS}

Group mean \pm standard deviation data are presented from all time points following discharge from rehabilitation for all participants in Figures 1-4 and Table 2. Walking speed increased by $0.12 \mathrm{~m} / \mathrm{s}$ between 1 and 6 months postdischarge from rehabilitation. This increase $(p=0.16)$, while not statistically significant, resulted in a large effect size $\left(\eta_{\mathrm{p}}{ }^{2}=0.27\right)$. 


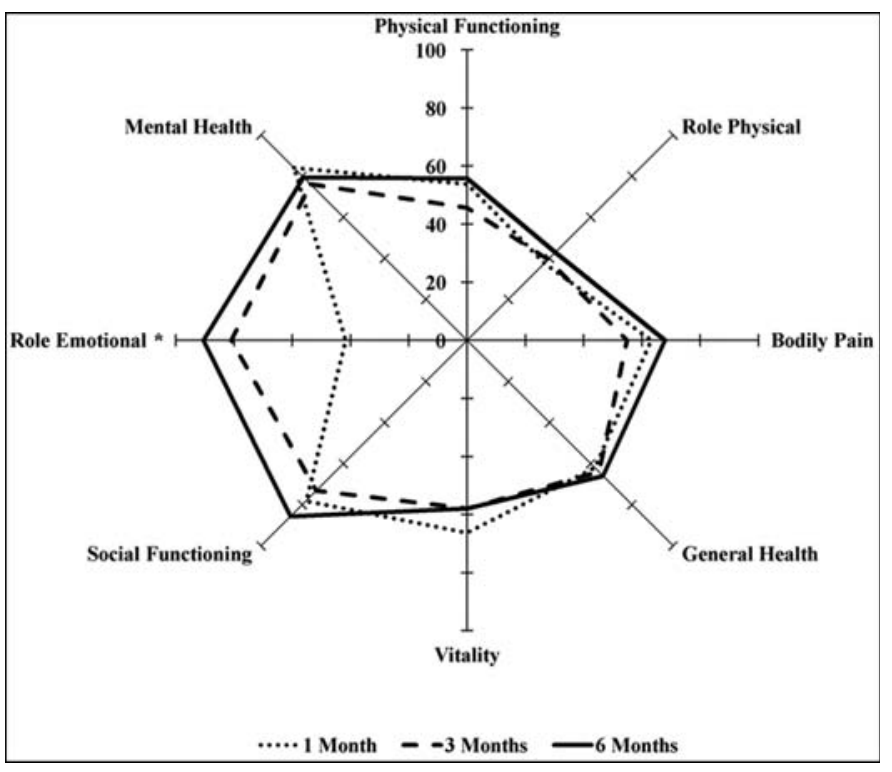

Figure 1.

Target plot of group mean transformed scores for eight scales of 36-Item Short Form Health Survey. Scores closer to outer border of plot relate to increased quality of life. *Significant at $p \leq 0.05$.

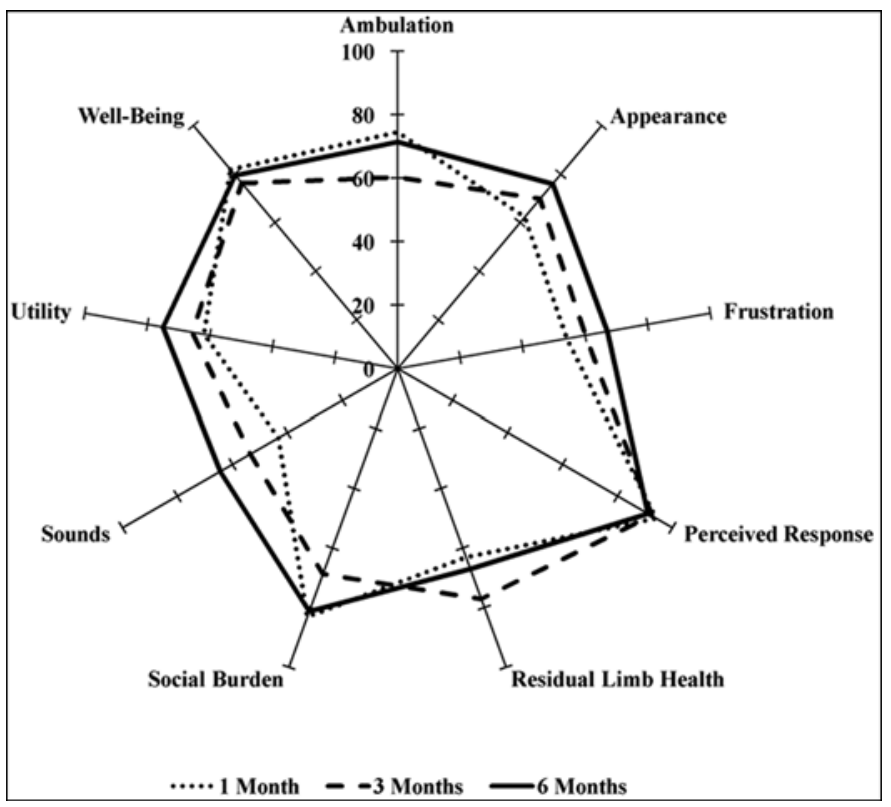

Figure 2.

Target plot of group mean scores for nine scales of Prosthesis Evaluation Questionnaire. Scores closer to outer border of plot relate to increased quality of life.

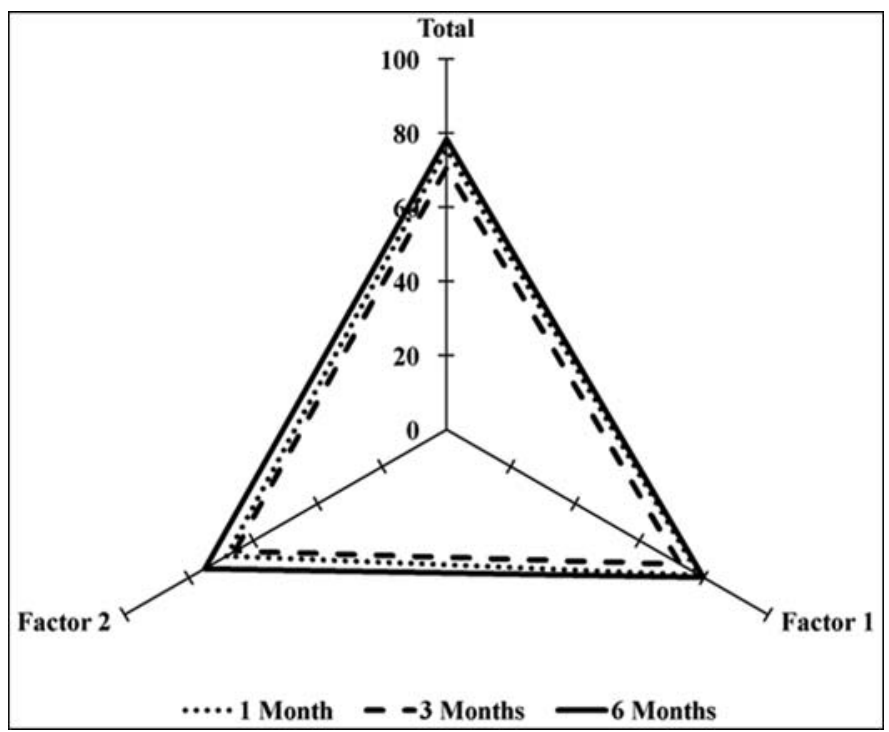

\section{Figure 3.}

Target plot of group mean scores for Modified Falls Efficacy Scale. Scores closer to outer border of plot relate to increased falls efficacy.

\section{Changes in Generic Health-Related Quality of Life}

Group mean scores for the eight scales, component summary, and total SF-36 are presented in Figure 1 and Table 2. With the exception of Vitality and Mental Health, the SF-36 scales displayed increases between 1 and 3 months and 3 and 6 months postdischarge from rehabilitation. A statistically significant increase for Role Emotional was reported between 1 and 6 months postdischarge from rehabilitation, where scores increased twofold $\left(p=0.03, \eta_{\mathrm{p}}{ }^{2}=0.44\right)$. Although many of the remaining increases were not statistically significant, large effect sizes were observed for changes in Physical Functioning $\left(\eta_{\mathrm{p}}{ }^{2}=0.16\right)$, Bodily Pain $\left(\eta_{\mathrm{p}}^{2}=0.36\right)$, Vitality $\left(\eta_{\mathrm{p}}^{2}=0.18\right)$, Social Functioning $\left(\eta_{\mathrm{p}}^{2}=0.24\right)$, and Mental Health $\left(\eta_{\mathrm{p}}^{2}=0.16\right)$.

With regard to the component summary scores, the MCS increased by 14.3 percent between 1 and 6 months postdischarge, and although this was not statistically significant, a large effect size was observed $\left(\eta_{\mathrm{p}}{ }^{2}=0.22\right)$. However, scores from the PCS were lower than the MCS and did not change significantly between 1 and 6 months postdischarge $(p=0.49)$. The observable increase in total SF-36 scores was not statistically significantly $(p=0.29)$, although a large effect size was produced $\left(\eta_{\mathrm{p}}{ }^{2}=0.19\right)$. 


\begin{tabular}{|c|c|c|c|c|c|c|c|c|c|c|c|c|c|c|c|c|c|}
\hline \multicolumn{6}{|c|}{$1 \mathrm{mo}$} & \multicolumn{6}{|c|}{$3 \mathrm{mo}$} & \multicolumn{6}{|c|}{$6 \mathrm{mo}$} \\
\hline 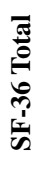 & $\begin{array}{l}0 \\
\sum_{\infty}^{n} \\
0 \\
0 \\
\omega \\
\omega\end{array}$ & $\begin{array}{l}\text { D } \\
\text { D } \\
0 \\
\infty \\
\frac{1}{\omega}\end{array}$ & 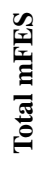 & 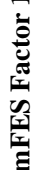 & 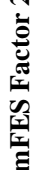 & $\begin{array}{l}\text { त्ञ } \\
0 \\
0 \\
0 \\
0 \\
0 \\
\frac{1}{\omega}\end{array}$ & $\begin{array}{l}0 \\
\sum_{0}^{\infty} \\
0 \\
0 \\
\omega \\
\omega\end{array}$ & $\begin{array}{l}n \\
0 \\
0 \\
0 \\
0 \\
\frac{1}{\omega}\end{array}$ & 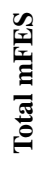 & 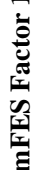 & 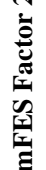 & 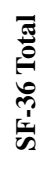 & $\begin{array}{l}0 \\
\sum_{0}^{\infty} \\
0 \\
0 \\
\infty \\
\infty\end{array}$ & $\begin{array}{l}\text { D } \\
0 \\
0 \\
\infty \\
\omega \\
\omega\end{array}$ & 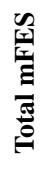 & 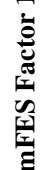 & 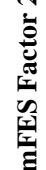 \\
\hline
\end{tabular}

\begin{tabular}{|c|c|c|c|c|c|c|c|c|c|c|c|c|c|c|c|c|c|c|}
\hline \multicolumn{19}{|l|}{$1 \mathrm{mo}$} \\
\hline Total mFES & $0.99^{*}$ & $0.96^{*}$ & $0.97^{\prime}$ & & & & & & & & & & & & & & & \\
\hline mFES Factor 2 & $0.95^{*}$ & $0.88^{*}$ & $0.95^{\prime}$ & & & & & & & & & & & & & & & \\
\hline \multicolumn{19}{|l|}{$3 \mathrm{mo}$} \\
\hline Total mFES & & & & & & & $0.99^{*}$ & $0.91^{*}$ & $0.97^{*}$ & & & & & & & & & \\
\hline mFES Factor 1 & & & & & & & $0.98^{*}$ & $0.90^{*}$ & $0.96^{*}$ & & & & & & & & & \\
\hline \multicolumn{19}{|l|}{$6 \mathrm{mo}$} \\
\hline Total mFES & & & & & & & & & & & & & $0.78^{*}$ & $0.84^{*}$ & $0.68^{*}$ & & & \\
\hline mFES Factor 1 & & & & & & & & & & & & & $0.77^{*}$ & $0.80^{*}$ & $0.72^{*}$ & & & \\
\hline mFES Factor 2 & & & & & & & & & & & & & $0.73^{*}$ & $0.86^{*}$ & 0.56 & & & \\
\hline Walking Speed & & & & & & & & & & & & & 0.57 & 0.51 & 0.48 & 0.27 & 0.29 & 0.23 \\
\hline
\end{tabular}

Figure 4.

Correlation table of the relationships between quality of life (QOL) and falls efficacy and between walking speed, QOL, and falls efficacy, with Pearson correlation coefficient $(r)$ and alpha ( $p$-value) stated. * Significant at $p \leq 0.05$. MCS = Mental Health Component summary, mFES = Modified Falls Efficacy Scale, PCS = Physical Component summary, SF-36 = 36-Item Short Form Health Survey.

\section{Changes in Prosthesis-Related Quality of Life}

Group mean scale scores from the PEQ are presented in Figure 2. Figure 2 displays the increases in scores for scales pertaining to participants' prostheses between 1, 3, and 6 months postdischarge from rehabilitation, Utility $\left(21.2 \%, \eta_{\mathrm{p}}^{2}=0.31\right)$, Sounds $\left(49.0 \%, \eta_{\mathrm{p}}{ }^{2}=0.26\right)$, Frustration $\left(24.0 \%, \eta_{\mathrm{p}}{ }^{2}=0.12\right)$, and Appearance $\left(21.8 \%, \eta_{\mathrm{p}}{ }^{2}=\right.$ 0.33 ); however, these did not reach statistical significance. The perceived reaction of close family members and friends (Perceived Response) was not reported to have changed significantly over time $(p=0.63)$ and was consistently the most positive score for participants in the current study. There were no significant changes on the remaining scales of the PEQ.

\section{Changes in Falls Efficacy}

Group mean overall, Factor One, and Factor Two mFES scores are presented in Table 2 and Figure 3. Overall falls efficacy did not change over time $\left(p=0.36, \eta_{\mathrm{p}}{ }^{2}=\right.$ $0.16)$. Further analysis highlighted that this trend was task independent, because no significant changes were observed over time for indoor (Factor One) $(p=0.34$, $\left.\eta_{\mathrm{p}}{ }^{2}=0.16\right)$ or outdoor tasks (Factor Two) $\left(p=0.33, \eta_{\mathrm{p}}{ }^{2}=\right.$ $0.17)$. This suggested that participants' self-perceived ability in executing ADLs without falling indoors or out- doors was similar as time passed following discharge from rehabilitation.

\section{Relationship Between Falls Efficacy and Quality of Life}

Strong positive relationships were observed when correlating QOL (Total SF-36) with overall falls efficacy (Total mFES) at 1 month $(r(5)=0.99, p<0.01), 3$ months $(r(5)=0.99, p<0.01)$, and 6 months $(r(5)=0.78, p=$ $0.02)$ postdischarge from rehabilitation (Figure 4). These strong positive relationships were also produced when correlating QOL with participants' falls efficacy of conducting both indoor (mFES Factor One) and outdoor (mFES Factor Two) activities at 1 month $(r(5)=0.99, p<$ $0.01 ; r(5)=0.95, p<0.01), 3$ months $(r(5)=0.98, p<$ $0.01 ; r(5)=0.99, p<0.01)$, and 6 months $(r(5)=0.77, p=$ $0.02 ; r(5)=0.73, p=0.03$ ) postdischarge (Figure 4).

When correlating falls efficacy with physical health (SF-36 PCS), statistically significant, strong positive relationships were observed at 1 month $(r(5)=0.97, p<0.01)$, 3 months $(r(5)=0.97, p<0.01)$, and 6 months $(r(5)=0.68$, $p=0.05$ ) postdischarge (Figure 4). Generally, this pattern was repeated when physical health was correlated with participants' falls efficacy for completing both indoor and outdoor activities at 1 month $(r(5)=0.96, p<0.01 ; r(5)=$ $0.95, p<0.01), 3$ months $(r(5)=0.96, p<0.01 ; r(5)=0.95$, 
Table 2.

Group mean \pm standard deviation scores, alpha values ( $p$-value), and effect sizes $\left(\eta_{\mathrm{p}}{ }^{2}\right)$ on SF-36 (generic health-related QOL), PEQ (prosthesisrelated QOL), and mFES (falls efficacy). Higher scores reflect increased QOL and increased falls efficacy.

\begin{tabular}{|c|c|c|c|c|c|c|}
\hline Instrument & Variable & $1 \mathrm{mo}$ & $3 \mathrm{mo}$ & $6 \mathrm{mo}$ & $p$-Value & $\eta_{p}^{2}$ \\
\hline \multirow[t]{8}{*}{ SF-36 } & Total SF-36 & $60.8 \pm 19.2$ & $61.5 \pm 19.3$ & $68.2 \pm 14.2$ & 0.29 & 0.19 \\
\hline & MCS & $66.4 \pm 15.9$ & $70.4 \pm 17.3$ & $75.9 \pm 11.1$ & 0.23 & 0.22 \\
\hline & PCS & $56.6 \pm 24.4$ & $52.3 \pm 24.4$ & $58.1 \pm 21.0$ & 0.49 & 0.11 \\
\hline & Role Physical & $37.5 \pm 32.3$ & $39.3 \pm 43.0$ & $42.9 \pm 37.4$ & 0.93 & 0.01 \\
\hline & Bodily Pain & $63.3 \pm 23.0$ & $54.9 \pm 20.1$ & $67.9 \pm 21.1$ & 0.07 & 0.36 \\
\hline & Social Functioning & $78.1 \pm 6.3$ & $73.2 \pm 19.7$ & $85.7 \pm 13.4$ & 0.20 & 0.24 \\
\hline & Role Emotional & $41.7 \pm 41.9$ & $81.0 \pm 26.2$ & $90.5 \pm 25.2$ & $0.03^{*}$ & 0.44 \\
\hline & Mental Health & $84.0 \pm 7.3$ & $76.0 \pm 14.2$ & $79.4 \pm 13.9$ & 0.36 & 0.16 \\
\hline \multirow[t]{5}{*}{ PEQ } & Ambulation & $74.5 \pm 6.0$ & $60.3 \pm 14.9$ & $71.4 \pm 18.0$ & 0.09 & 0.33 \\
\hline & Social Burden & $83.1 \pm 9.3$ & $68.7 \pm 18.7$ & $81.3 \pm 26.0$ & 0.15 & 0.27 \\
\hline & Sounds & $43.3 \pm 19.1$ & $53.6 \pm 31.6$ & $64.5 \pm 29.1$ & 0.17 & 0.26 \\
\hline & Utility & $61.9 \pm 19.9$ & $65.7 \pm 18.1$ & $75.0 \pm 15.0$ & 0.11 & 0.31 \\
\hline & Well-Being & $81.9 \pm 6.6$ & $76.3 \pm 16.3$ & $79.5 \pm 16.4$ & 0.62 & 0.08 \\
\hline \multirow[t]{4}{*}{ mFES } & Total mFES & $75.7 \pm 17.2$ & $70.6 \pm 17.5$ & $78.4 \pm 15.9$ & 0.36 & 0.16 \\
\hline & mFES Factor 1 & $78.7 \pm 17.4$ & $72.6 \pm 17.3$ & $79.8 \pm 14.8$ & 0.34 & 0.16 \\
\hline & mFES Factor 2 & $68.3 \pm 17.2$ & $65.7 \pm 18.7$ & $75.0 \pm 25.0$ & 0.33 & 0.17 \\
\hline & Walking Speed & $0.92 \pm 0.17$ & $1.01 \pm 0.17$ & $1.04 \pm 0.21$ & 0.16 & 0.27 \\
\hline
\end{tabular}

$p<0.01)$, and 6 months $(r(5)=0.72, p=0.03 ; r(5)=0.56$, $p=0.09)$ postdischarge (Figure 4).

Mental health (SF-36 MCS) also produced statistically significant, strong positive relationships when correlated with overall falls efficacy at 1 month $(r(5)=0.96$, $p<0.01), 3$ months $(r(5)=0.91, p<0.01)$, and 6 months $(r(5)=0.84, p=0.01)$ postdischarge (Figure 4). This trend was continued when mental health was correlated with participants' falls efficacy for undertaking both indoor and outdoor activities at 1 month $(r(5)=0.98, p<$ $0.01 ; r(5)=0.88, p<0.01), 3$ months $(r(5)=0.90, p<$ $0.01 ; r(5)=0.92, p<0.01)$, and 6 months $(r(5)=0.80$, $p=0.02 ; r(5)=0.86, p<0.01)$ postdischarge (Figure 4).

\section{Relationship Between Walking Speed, Quality of Life, and Falls Efficacy}

No statistically significant correlational relationships existed between walking speed and any of the indices of
QOL or falls efficacy (Figure 4). However, interestingly, the difference in the strength of correlation coefficients between walking speed and physical health and walking speed and mental health was greater at 1 month $(r=0.23$ in favor of physical health) than at 6 months postdischarge ( $r=0.03$ in favor of mental health).

\section{DISCUSSION}

The scientific literature has reported various aspects of QOL in people with transtibial amputations [9-13]. However, the longitudinal development of QOL and falls efficacy following discharge from rehabilitation has not been investigated.

In the current study, mental health, as represented by the SF-36 MCS score, improved between 1 and 6 months postdischarge from rehabilitation. Although this increase 
was not statistically significant, it was likely clinically meaningful given the magnitude of the associated effect size [35-36]. In agreement with previous reports, SF-36 MCS scores were higher than PCS scores [9-13]. The findings from the current study correspond with previous reports [11-12], although equivocal findings suggest that further research is required [9-10,27]. Allied to this, prosthesis-related QOL tended to show greater improvements and magnitudes of effect sizes in scales pertaining specifically to amputees' prostheses. These improvements may be expected because of the stabilization of the condition of the residuum coupled with further adjustments to the prosthetic components and socket. Importantly, the current results support the use of a population-specific QOL measure that assesses disease-specific health concerns beyond general mental and physical health.

The lack of significant improvements in self-reported physical health, increase in walking speed, and nonsignificant correlation between these variables provide some support for the response phenomena hypothesis previously reported [12]. Given that mobility, as reflected by walking speed, at 6 months following discharge was slower than that reported with more experienced prosthetic users [3], future gains in physical functioning could be predicted, and thus, expectations regarding future improvements may have been heightened. Therefore, when reporting on their physical health, participants may have reflected on their current level in relation to a level they were expecting to achieve. Even with improvements in mobility and subsequent physical health, the status quo may not have matched an individual's expectation; thus, the self-reported physical health remained unchanged. Another interpretation could be acceptance on the part of the person with amputation that his or her physical functioning was decreased when compared with a nondisabled individual, because questions related to the general health scale required the amputees to reference their health state to other people. Therefore, reports of physical health were reduced, although mental health increased as the social and psychological impact of amputation decreased. Findings from a previous investigation of QOL in people with lower-limb amputations during rehabilitation reported a positive link between walking ability and QOL [20]. However, this trend did not appear fully applicable postdischarge from rehabilitation as displayed by the moderate, not statistically significant relationship between physical health (SF-36 PCS score) and walking speed at 6 months postdischarge from rehabilitation.

The perceived response of "significant others" was consistently the most positive response score from prosthesis-related QOL assessment and did not change significantly over time, indicating that participants had good support from family and friends. An investigation of the effect of perceived response on mental health would be interesting, as it may reveal this to be an important factor affecting people with lower-limb amputations' mental health following discharge from rehabilitation. This would have implications for people with amputations who may not have the perceived social support observed in the current study group.

Falls efficacy did not change significantly over time; however, strong positive relationships were reported when indices of falls efficacy were correlated with indices of QOL. The results from the current study support previous literature linking falls efficacy to QOL [22-23]. However, previous studies by Miller et al. assessed QOL using only the Mobility subscale of the PEQ, reflecting QOL in a physical sense [22-23]. Results from the current study suggested that falls efficacy was also linked to the mental health aspect of QOL. Therefore, assessment of mental health should be incorporated when relating QOL to falls efficacy in people with lower-limb amputations. The relationship between QOL and falls efficacy in this population warrants further investigation.

Analyses of participants' falls efficacy while undertaking indoor (Factor One) and outdoor (Factor Two) activities also displayed no significant changes over time and were similar at 6 months postdischarge. Together, these findings suggested that neither factor had an increased contribution to overall falls efficacy in people with lower-limb amputations. However, reduced falls efficacy while undertaking outdoor activities compared with indoor activities has been observed in elderly fallers [30]. Given the increased falls rate in people with lowerlimb amputations, the relationship between mobility and the different factors of falls efficacy would benefit from further investigation, because a disparity between the falls efficacy of performing indoor versus outdoor activities may be expected [22-23,30].

The lack of statistical significance observed in the SF-36 analyses could be hypothesized as being the result of a lack of sensitivity in the measurement tool when used within the current participant group. However, the SF-36 has been utilized previously within a lower-limb 
amputee population [9-10,25-26]. Equally, the large effect sizes and lack of statistical significance of results obtained from the PEQ and mFES may reflect reduced statistical power as a result of the relatively small sample size. Thus, results from the current study could be treated as exploratory in nature, forming the basis for future investigation. Limitations related to sample size and recruitment issues are likely to be an inherent problem when investigating the clinical population in question.

\section{CONCLUSIONS}

The current study has provided a novel insight into how QOL and falls efficacy develop once people with lower-limb amputations are discharged from a rehabilitation program. Observable and, perhaps, clinically meaningful changes in QOL and falls efficacy were reported, resulting in large effect sizes. However, as a result of the small sample size, many of these changes were not statistically significant. Mental health was increased in comparison with physical health, suggesting that increases in physical health over time would be required to elicit further increases in overall QOL. Changes in indices of falls efficacy were seen to be equally linked to physical and mental health, and this would suggest that further increases in either aspect of health over time may improve falls efficacy. The changes in overall falls efficacy were mirrored by the changes observed in falls efficacy during indoor (Factor One) and outdoor (Factor Two) activities. Neither factor seemed to contribute more than the other to overall falls efficacy. Studies employing greater participant numbers may further elucidate the novel effects and relationships discussed in the current study.

\section{ACKNOWLEDGMENTS}

\author{
Author Contributions: \\ Study concept and design: C. T. Barnett, N. Vanicek, R. C. Polman. \\ Acquisition of data: C. T. Barnett. \\ Analysis and interpretation of data: C. T. Barnett. \\ Drafting of manuscript: C. T. Barnett, N. Vanicek, R. C. Polman. \\ Critical revision of manuscript for important intellectual content: \\ C. T. Barnett, N. Vanicek, R. C. Polman. \\ Statistical analysis: C. T. Barnett. \\ Obtained funding: C. T. Barnett. \\ Administrative, technical, or material support: C. T. Barnett. \\ Study supervision: C. T. Barnett, N. Vanicek, R. C. Polman.
}

Financial Disclosures: The authors have declared that no competing interests exist.

Funding/Support: This material was based on work supported by the Owen Shaw Award from the Circulation Foundation, United Kingdom.

Additional Contributions: The authors would like to thank Mrs. Amanda Hancock, Mrs. Barbara Brown, and Mrs. Lynne Smith for their help with patient recruitment.

Institutional Review: Participants gave written informed consent when attending data collection sessions as part of a wider study. Ethical approval was obtained from the Local Research Ethics Committee (reference number: 08/H1304/10).

Participant Follow-Up: The authors do not plan to inform participants of the publication of this study, although upon request, participants will be directed to a link where the article will be available.

\section{REFERENCES}

1. Winter DA, Sienko SE. Biomechanics of below-knee amputee gait. J Biomech. 1988;21(5):361-67.

[PMID:3417688]

http://dx.doi.org/10.1016/0021-9290(88)90142-X

2. Hill SW, Patla AE, Ishac MG, Adkin AL, Supan TJ, Barth DG. Kinematic patterns of participants with a below-knee prosthesis stepping over obstacles of various heights during locomotion. Gait Posture. 1997;6:186-92. http://dx.doi.org/10.1016/S0966-6362(97)01120-X

3. Sanderson DJ, Martin PE. Lower extremity kinematic and kinetic adaptations in unilateral below-knee amputees during walking. Gait Posture. 1997;6:126-36. http://dx.doi.org/10.1016/S0966-6362(97)01112-0

4. Buckley JG, O’Driscoll D, Bennett SJ. Postural sway and active balance performance in highly active lower-limb amputees. Am J Phys Med Rehabil. 2002;81(1):13-20. [PMID:11807327] http://dx.doi.org/10.1097/00002060-200201000-00004

5. Vanicek N, Strike S, McNaughton L, Polman R. Postural responses to dynamic perturbations in amputee fallers versus nonfallers: a comparative study with able-bodied subjects. Arch Phys Med Rehabil. 2009;90(6):1018-25. [PMID:19480879] http://dx.doi.org/10.1016/j.apmr.2008.12.024

6. Ware JE Jr, Gandek B. Overview of the SF-36 health survey and the International Quality of Life Assessment (IQOLA) project. J Clin Epidemiol. 1998;51(11):903-12. [PMID:9817107] http://dx.doi.org/10.1016/S0895-4356(98)00081-X

7. Garratt A, Schmidt L, Mackintosh A, Fitzpatrick R. Quality of life measurement: bibliographic study of patient assessed health outcome measures. BMJ. 2002;324(7351):1417. [PMID:12065262] http://dx.doi.org/10.1136/bmj.324.7351.1417 
8. Sinha R, van den Heuvel WJ, Arokiasamy P. Factors affecting quality of life in lower limb amputees. Prosthet Orthot Int. 2011;35(1):90-96. [PMID:21515894] http://dx.doi.org/10.1177/0309364610397087

9. van der Schans CP, Geertzen JH, Schoppen T, Dijkstra PU. Phantom pain and health-related quality of life in lower limb amputees. J Pain Symptom Manage. 2002;24(4):429-36. [PMID:12505212] http://dx.doi.org/10.1016/S0885-3924(02)00511-0

10. Pezzin LE, Dillingham TR, MacKenzie EJ. Rehabilitation and the long-term outcomes of persons with trauma-related amputations. Arch Phys Med Rehabil. 2000;81(3):292-300. [PMID:10724073] http://dx.doi.org/10.1016/S0003-9993(00)90074-1

11. Asano M, Rushton P, Miller WC, Deathe BA. Predictors of quality of life among individuals who have a lower limb amputation. Prosthet Orthot Int. 2008;32(2):231-43. [PMID:18569891] http://dx.doi.org/10.1080/03093640802024955

12. Zidarov D, Swaine B, Gauthier-Gagnon C. Quality of life of persons with lower-limb amputation during rehabilitation and at 3-month follow-up. Arch Phys Med Rehabil. 2009;90(4):634-45. [PMID:19345780] http://dx.doi.org/10.1016/j.apmr.2008.11.003

13. Legro MW, Reiber G, del Aguila M, Ajax MJ, Boone DA, Larsen JA, Smith DG, Sangeorzan B. Issues of importance reported by persons with lower limb amputations and prostheses. J Rehabil Res Dev. 1999;36(3):155-63. [PMID:10659798]

14. Sinha R, Van Den Heuvel WJ. A systematic literature review of quality of life in lower limb amputees. Disabil Rehabil. 2011;33(11):883-99. [PMID:20825359] http://dx.doi.org/10.3109/09638288.2010.514646

15. Penn-Barwell JG. Outcomes in lower limb amputation following trauma: a systematic review and meta-analysis. Injury. 2011;42(12):1474-79. [PMID:21831371] http://dx.doi.org/10.1016/j.injury.2011.07.005

16. Gallagher P, Maclachlan M. The Trinity Amputation and Prosthesis Experience Scales and quality of life in people with lower-limb amputation. Arch Phys Med Rehabil. 2004;85(5):730-36. [PMID:15129396] http://dx.doi.org/10.1016/j.apmr.2003.07.009

17. Mazari FA, Mockford K, Barnett C, Khan JA, Brown B, Smith L, Polman RC, Hancock A, Vanicek NK, Chetter IC. Hull early walking aid for rehabilitation of transtibial amputees - randomized controlled trial (HEART). J Vasc Surg. 2010;52(6):1564-71. [PMID:20855178]

http://dx.doi.org/10.1016/j.jvs.2010.07.006

18. Hammarlund CS, Carlström M, Melchior R, Persson BM. Prevalence of back pain, its effect on functional ability and health-related quality of life in lower limb amputees secondary to trauma or tumour: a comparison across three lev- els of amputation. Prosthet Orthot Int. 2011;35(1):97-105. [PMID:21515895]

http://dx.doi.org/10.1177/0309364610389357

19. Deans SA, McFadyen AK, Rowe PJ. Physical activity and quality of life: A study of a lower-limb amputee population. Prosthet Orthot Int. 2008;32(2):186-200.

[PMID: 18569887]

http://dx.doi.org/10.1080/03093640802016514

20. Brooks D, Parsons J, Hunter JP, Devlin M, Walker J. The 2minute walk test as a measure of functional improvement in persons with lower limb amputation. Arch Phys Med Rehabil. 2001;82(10):1478-83. [PMID:11588757] http://dx.doi.org/10.1053/apmr.2001.25153

21. Tinetti ME, Mendes de Leon CF, Doucette JT, Baker DI. Fear of falling and fall-related efficacy in relationship to functioning among community-living elders. J Gerontol. 1994;49(3):M140-47. [PMID:8169336] http://dx.doi.org/10.1093/geronj/49.3.M140

22. Miller WC, Deathe AB, Speechley M, Koval J. The influence of falling, fear of falling, and balance confidence on prosthetic mobility and social activity among individuals with a lower extremity amputation. Arch Phys Med Rehabil. 2001;82(9):1238-44. [PMID:11552197] http://dx.doi.org/10.1053/apmr.2001.25079

23. Miller WC, Speechley M, Deathe B. The prevalence and risk factors of falling and fear of falling among lower extremity amputees. Arch Phys Med Rehabil. 2001;82(8): 1031-37. [PMID:11494181] http://dx.doi.org/10.1053/apmr.2001.24295

24. Ware JE, Snow KK, Kosinski M, Gandek B. SF-36 health survey: manual and interpretation guide. Boston (MA): The Health Institute, New England Medical Center; 1993.

25. Hoogendoorn JM, van der Werken C. Grade III open tibial fractures: functional outcome and quality of life in amputees versus patients with successful reconstruction. Injury. 2001;32(4):329-34. [PMID:11325370] http://dx.doi.org/10.1016/S0020-1383(00)00250-3

26. Meikle B, Devlin M, Garfinkel S. Interruptions to amputee rehabilitation. Arch Phys Med Rehabil. 2002;83(9):1222-28. [PMID:12235601] http://dx.doi.org/10.1053/apmr.2002.33657

27. Legro MW, Reiber GD, Smith DG, del Aguila M, Larsen J, Boone D. Prosthesis evaluation questionnaire for persons with lower limb amputations: assessing prosthesis-related quality of life. Arch Phys Med Rehabil. 1998;79(8):931-38. [PMID:9710165] http://dx.doi.org/10.1016/S0003-9993(98)90090-9

28. Deathe AB, Miller WC. The L test of functional mobility: measurement properties of a modified version of the timed "up \& go" test designed for people with lower-limb amputations. Phys Ther. 2005;85(7):626-35. [PMID:15982169] 
29. Kaufman KR, Levine JA, Brey RH, McCrady SK, Padgett DJ, Joyner MJ. Energy expenditure and activity of transfemoral amputees using mechanical and microprocessorcontrolled prosthetic knees. Arch Phys Med Rehabil. 2008; 89(7):1380-85. [PMID:18586142]

http://dx.doi.org/10.1016/j.apmr.2007.11.053

30. Hill KD, Schwarz JA, Kalogeropoulos AJ, Gibson SJ. Fear of falling revisited. Arch Phys Med Rehabil. 1996;77(10): 1025-29. [PMID:8857881] http://dx.doi.org/10.1016/S0003-9993(96)90063-5

31. Delbaere K, Crombez G, van Haastregt JC, Vlaeyen JW. Falls and catastrophic thoughts about falls predict mobility restriction in community-dwelling older people: A structural equation modelling approach. Aging Ment Health. 2009;13(4):587-92. [PMID:19629784] http://dx.doi.org/10.1080/13607860902774444

32. Vrantsidis F, Hill KD, Moore K, Webb R, Hunt S, Dowson L. Getting grounded gracefully: effectiveness and acceptability of Feldenkrais in improving balance. J Aging Phys Act. 2009;17(1):57-76. [PMID:19299839]

33. Chamberlin ME, Fulwider BD, Sanders SL, Medeiros JM. Does fear of falling influence spatial and temporal gait parameters in elderly persons beyond changes associated with normal aging? J Gerontol A Biol Sci Med Sci. 2005; 60(9):1163-67. [PMID:16183957] http://dx.doi.org/10.1093/gerona/60.9.1163

34. Cohen J. Statistical power analysis for the behavioral sciences. Hillsdale (NJ): Lawrence Erlbaum Associates; 1988.
35. Kazis LE, Anderson JJ, Meenan RF. Effect sizes for interpreting changes in health status. Med Care. 1989;27(3 Suppl):S178-89. [PMID:2646488] http://dx.doi.org/10.1097/00005650-198903001-00015

36. Norman GR, Sloan JA, Wyrwich KW. Interpretation of changes in health-related quality of life: the remarkable universality of half a standard deviation. Med Care. 2003; 41(5):582-92. [PMID:12719681] http://dx.doi.org/10.1097/01.MLR.0000062554.74615.4C

Submitted for publication October 28, 2011. Accepted in revised form July 9, 2012.

This article and any supplementary material should be cited as follows:

Barnett CT, Vanicek N, Polman RC. Temporal adaptations in generic and population-specific quality of life and falls efficacy in men with recent lower-limb amputations. J Rehabil Res Dev. 2013;50(3):437-48.

http://dx.doi.org/10.1682/JRRD.2011.10.0205

ResearcherID/ORCID: Cleveland T. Barnett, PhD: D2884-2013; Natalie Vanicek, PhD: D-1860-2013; Remco C. J. Polman, PhD: D-1877-2013

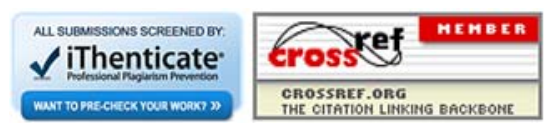


